\title{
Acúmulo e partição de biomassa e macronutrientes de cultivares de feijão- vagem em cultivo protegido fertirrigado
}

\author{
Natalia Fernandes Carr ${ }^{1}$, Renan Ribeiro Barzan ${ }^{2}$, Luiz Henrique Campos de Almeida ${ }^{2}$, Gustavo Adolfo de \\ Freitas Fregonezi ${ }^{3},{ }^{2}$ Hideaki Wilson Takahashi \\ ${ }^{1}$ Universidade de São Paulo - USP, SP. Universidade Estadual de Londrina - UEL, PR. ${ }^{3}$ Centro Universitário Filadélfia - \\ UNIFIL, PR. E-mail: renan barzan@hotmail.com
}

\begin{abstract}
Resumo
Para um melhor manejo da fertirrigação em cultivos protegidos de olerícolas, como o feijão-vagem, faz-se necessário conhecer a demanda nutricional dessas plantas. Portanto, objetivou-se caracterizar o acúmulo de biomassa e macronutrientes por genótipos de feijão-vagem em cultivo protegido fertirrigado. Para tanto, foi conduzido experimento inteiramente casualizado em casa-de-vegetação, com os genótipos UEL-1 e Alessa, cultivados em vasos plásticos com areia grossa como substrato e fertirrigação por micro-aspersão. A cada dez dias, as plantas foram coletadas e mensurado a massa de matéria seca e a concentração de nitrogênio $(N)$, fósforo $(P)$, potássio $(K)$, cálcio $(\mathrm{Ca})$, magnésio $(\mathrm{Mg})$ e enxofre $(\mathrm{S})$ nos tecidos vegetais, ajustando-se o seu acúmulo ao longo do tempo por meio do modelo gaussiano. A produtividade de vagens frescas $\left(\mathrm{kg} \mathrm{m}^{-2}\right)$ também foi medida. $O$ acúmulo de biomassa e macronutrientes foi intensificado a partir dos 20 dias após a emergência (DAE), atingindo valores máximos próximo aos 50 DAE. O genótipo Alessa teve maior acúmulo de biomassa e macronutrientes, enquanto UEL-1 foi mais produtivo em vagens frescas, caracterizando maior eficiência no uso dos nutrientes. Para ambos genótipos, o $\mathrm{N}$ teve o maior acúmulo, seguido por K, Ca, P, S e Mg.
\end{abstract}

Palavras-chave: Phaseolus vulgaris L.; nutrição vegetal; absorção; redistribuição.

Accumulation and partitioning of biomass and macronutrients of bush snap bean genotypes in semihydroponic system

\begin{abstract}
For a better management of fertigation in protected cultivation of vegetables such as snap beans, it is important to know the nutritional requirements of the plants. Thus, we aimed to characterize the biomass and macronutrients accumulation of bush snap beans genotypes. For that, an experiment was carried out in greenhouse, where the genotypes UEL-1 and Alessa were grown in plastic pots with coarse sand as substrate and fertigation by micro sprinklers. Each ten days, plants were sampled and measured the dry matter and the concentrations of elements such as nitrogen $(\mathrm{N})$, phosphorus $(\mathrm{P})$, potassium $(\mathrm{K})$, calcium $(\mathrm{Ca})$, magnesium $(\mathrm{Mg}$ ) and sulfur $(\mathrm{S})$ for different plant parts, adjusting their accumulation over time by the gaussian model. The fresh pods yield $\left(\mathrm{kg} \mathrm{m}^{-2}\right)$ was also evaluated. The accumulation of biomass and macronutrients was intensified from 20 days after emergence (DAE), reaching maximum values near 50 DAE. The genotype Alessa presented a higher overall accumulation, while UEL-1 was more productive regarding fresh pods, characterizing such genotype as more efficient for using the macronutrients. For both genotypes, $\mathrm{N}$ had the highest accumulation, followed by $\mathrm{K}, \mathrm{Ca}, \mathrm{P}, \mathrm{S}$ and $\mathrm{Mg}$.
\end{abstract}

Keywords: Phaseolus vulgaris L.; plant nutrition; absorption; redistribution. 


\section{Introdução}

A produção de feijão-vagem (Phaseolus vulgaris L.) no Brasil ocorre, em sua maioria, em pequenas propriedades de agricultura familiar, aproveitando-se o sistema de tutoramento utilizado na produção de tomate e pepino para a rotação de culturas. Os principais cultivares recomendados têm crescimento indeterminado e, apesar de atingirem maiores produções que os genótipos determinados, também necessitam mais cuidados na condução da cultura, demandando maior mão-de-obra. Além disso, o ciclo prolongado com crescimento vegetativo contínuo dos cultivares indeterminados os tornam mais sujeitos à ocorrência de pragas e doenças (MOREIRA et al., 2009).

Nas regiões subtropicais, onde as exigências termo climáticas do feijão-vagem podem não ser atendidas em determinadas épocas do ano, o cultivo protegido é colocado como uma alternativa para contornar essas limitações (HELDWEIN et al., 2010). No entanto, a ocorrência de salinização do solo, decorrente de fertilização excessiva, é comum neste tipo de cultivo, o que abre caminho para os sistemas de fertirrigação em substratos (FERNANDES et al., 2002).

De acordo com Silva (2014), o manejo da fertirrigação é feito tradicionalmente com base na dinâmica de absorção de nutrientes. As quantidades de fertilizantes a serem aplicadas por solução nutritiva podem ser parceladas a fim de prover a demanda de nutrientes pelas plantas em função do acúmulo e redistribuição ao longo do ciclo.

Apesar da importância de se conhecer estes aspectos, há uma carência de estudos voltados à caracterização do acúmulo de biomassa e nutrientes minerais em feijão-vagem de crescimento determinado, podendo-se destacar o trabalho desenvolvido por Barzan et al. (2016) com o genótipo UEL-1, que, no entanto, foi conduzido em condições de campo. Além disso, conforme relatado por Araújo e Teixeira (2012) para o feijoeiro, diferenças genotípicas podem proporcionar variabilidade na produção de biomassa e conteúdo de nutrientes, mantendo relação estreita com a produtividade.

Dessa forma, objetivou-se com o presente trabalho caracterizar o acúmulo de biomassa e macronutrientes, identificando as quantidades requeridas e a compartimentalização por genótipos de feijão- vagem de crescimento determinado em cultivo protegido fertirrigado.

\section{Material e Métodos}

$O$ experimento foi conduzido em casa-devegetação modelo 'teto em arco' com cobertura de plástico (PEBD com $150 \mu \mathrm{m}$ de espessura), localizada no Centro de Ciências Agrárias da Universidade Estadual de Londrina (UEL),

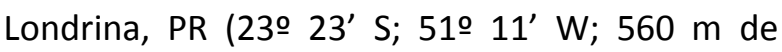
altitude), durante os meses de setembro a novembro.

0 delineamento experimental foi inteiramente casualizado, utilizando-se dois genótipos de feijão-vagem de crescimento determinado, UEL-1 e Alessa, cultivados em vasos plásticos contendo $5,0 \mathrm{dm}^{3}$ de areia grossa (>800 $\mathrm{g} \mathrm{kg}^{-1}$ de partículas entre 0,2 e $2,0 \mathrm{~mm}$ de diâmetro) como substrato. Os vasos foram dispostos em linhas com três metros de comprimento, espaçados em $0,25 \times 0,5 \mathrm{~m}$. Foram semeadas cinco sementes por vaso, realizando-se o desbaste após a emergência das plântulas, deixando apenas duas por vaso.

Os vasos receberam apenas água após a semeadura e durante os primeiros 7 dias posteriores a emergência. A fertirrigação com solução nutritiva teve início após este período, com uma concentração relativa a $30 \%$ da solução padrão (Tabela 1), elevando-se para 50 e $100 \%$ aos 14 e 21 dias após a emergência (DAE), respectivamente. Os sais utilizados para 0 preparo da solução nutritiva foram $\mathrm{NH}_{4} \mathrm{H}_{2} \mathrm{PO}_{4}(0,2$ $\left.\mathrm{g} \mathrm{L}^{-1}\right), \mathrm{Ca}\left(\mathrm{NO}_{3}\right)_{2}\left(0,8 \mathrm{~g} \mathrm{~L}^{-1}\right), \mathrm{CaCl}_{2}\left(0,3 \mathrm{~g} \mathrm{~L}^{-1}\right)$, $\mathrm{MgSO}_{4} .7 \mathrm{H}_{2} \mathrm{O}\left(0,3 \mathrm{~g} \mathrm{~L}^{-1}\right), \mathrm{KNO}_{3}\left(0,4 \mathrm{~g} \mathrm{~L}^{-1}\right)$, além dos fertilizantes comerciais Rexolin BRA ${ }^{\circledR}\left(0,03 \mathrm{~g} \mathrm{~L}^{-1}\right)$ e Rexolin $M 48 \AA\left(0,03 \mathrm{~g} \mathrm{~L}^{-1}\right)$, como fonte de micronutrientes.

O sistema de fertirrigação foi composto por tanques com capacidade para $250 \mathrm{~L}$ de solução nutritiva, bombas $(0,216 \mathrm{MPa}$ e 0,245 $\mathrm{kW})$, mangueiras de polietileno e microaspersores. A vazão foi regulada em $4,0 \pm 0,5 \mathrm{~cm}^{3}$ $\mathrm{s}^{-1}$, utilizando-se um timer para acionamento das bombas por 40 segundos, de três a cinco vezes ao dia, conforme demanda evapotranspirativa das plantas em função da temperatura no interior da estrutura de cultivo protegido.

A cada dez dias após a emergência (DAE), foram coletadas 15 plantas por genótipo, para avaliação do acúmulo de massa de matéria seca e de macronutrientes nas diferentes partes das 
plantas (raízes, hastes, folhas e vagens). A cada época de coleta, os tecidos vegetais foram secos em estufa de circulação forçada de ar a 65 ㄷ por $72 \mathrm{~h}$. A massa de matéria seca foi obtida por meio da pesagem dos tecidos em uma balança semianalítica de precisão. Após, as amostras foram trituradas em moinho tipo Wiley e submetidas a digestão ácida para posterior determinação analítica das concentrações $\left(\mathrm{g} \mathrm{kg}^{-1}\right)$ de nitrogênio
(N) pelo método de Kjeldahl; fósforo (P) por espectrofotometria; potássio (K) por fotometria de chama; enxofre $(S)$ por turbidimetria; cálcio (Ca) e magnésio ( $\mathrm{Mg}$ ) por espectrometria de absorção atômica, como descrito por Malavolta et al. (1997).

Tabela 1. Concentração de nutrientes na solução nutritiva padrão (condutividade elétrica de $2,0 \mathrm{dS} \mathrm{m}^{-1}$ ) utilizada para o cultivo dos genótipos de feijão-vagem de crescimento determinado, UEL-1 e Alessa, em ambiente protegido com fertirrigação.

\begin{tabular}{|c|c|c|c|c|c|}
\hline \multicolumn{6}{|c|}{ Macronutrientes } \\
\hline $\mathrm{N}$ & P & K & $\mathrm{Ca}$ & $\mathrm{Mg}$ & $S$ \\
\hline \multicolumn{6}{|c|}{$\begin{array}{l}-1 \\
-1\end{array}$} \\
\hline 215 & 54 & 154 & 304 & 30 & 40 \\
\hline \multicolumn{6}{|c|}{ Micronutrientes } \\
\hline $\mathrm{Cu}$ & $\mathrm{Zn}$ & $\mathrm{Mn}$ & $\mathrm{Fe}$ & Mo & B \\
\hline \multicolumn{6}{|c|}{$\begin{array}{l}-1 \\
\end{array}$} \\
\hline 110 & 1010 & 740 & 2750 & 10 & 630 \\
\hline
\end{tabular}

Para a determinação do acúmulo dos macronutrientes nas respectivas partes das plantas, em cada época do ciclo, realizou-se a multiplicação do valor da massa de matéria seca (g planta ${ }^{-1}$ ) pela concentração de cada elemento $\left(\mathrm{g} \mathrm{kg}^{-1}\right)$ nos diferentes tecidos. $\mathrm{O}$ acúmulo foi ajustado em função do tempo com auxílio do software SigmaPlot ${ }^{\circledR}$ v.10, por meio do modelo Gaussiano com três parâmetros (Equação 1), como realizado por Zobiole et al. (2010), em que: $\widehat{y}=$ acúmulo $\left(\mathrm{mg}\right.$ planta $\left.{ }^{-1}\right) ; a=$ valor de máximo acúmulo (mg planta ${ }^{-1}$ ); $x 0=$ valor de $x$, em dias após a emergência, que corresponde ao máximo acúmulo; $b=$ amplitude do intervalo de $x$ entre o ponto de inflexão (quando a taxa diária de acúmulo, ainda que positiva, começa a decrescer) e o valor de $x 0$.

Eq. 1

$$
\hat{y}=a e^{\left[-0,5\left(\frac{x-x 0}{b}\right)^{2}\right]}
$$

O desempenho produtivo foi avaliado por meio da colheita de 10 plantas, aleatoriamente, de cada genótipo, aos $60 \mathrm{DAE}$, pesando-se a massa fresca de vagens em balança semi-analítica de precisão e convertendo em $\mathrm{kg} \mathrm{m}^{-2}$, de acordo com a área ocupada pelas plantas (8 plantas por $\mathrm{m}^{2}$ ).

\section{Resultados e Discussão}

Ambos os genótipos apresentaram um acúmulo lento de matéria seca até os 20 DAE (correspondendo ao estádio de desenvolvimento V4), a partir do qual houve um incremento na síntese de biomassa de órgãos vegetativos, enquanto a produção de vagens teve início próximo aos 40 DAE (Figuras 1A e 1B). 
Figura 1. Acúmulo de Matéria Seca (MS, g planta ${ }^{-1}$ ) dos genótipos de feijão-vagem UEL-1 (A) e Alessa (B) nas diferentes partes da planta ao longo do ciclo, em cultivo protegido com fertirrigação.

A.

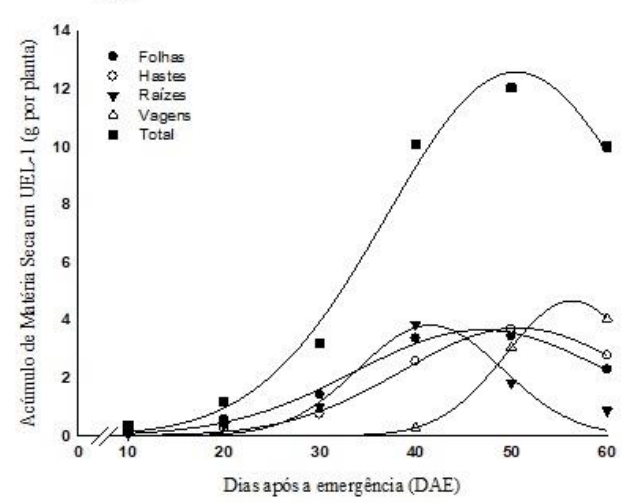

O pico de matéria seca da planta inteira ocorreu aos 50 e aos 49 DAE para UEL-1 e Alessa, respectivamente, com 0 segundo genótipo apresentando maiores valores (Tabela 2). A perda de biomassa total após esse período pode ser parcialmente explicada por uma fotossíntese líquida negativa, devido a redução da área foliar em plena atividade e aumento na oxidação de compostos de carbono frente à fotossíntese bruta (ENGELS et al., 2011). Comportamento semelhante foi observado por Gomes et al. (2000) ao estudar genótipos de feijão comum. Os autores reportaram uma redução na taxa assimilatória líquida, em função de menores índices de área foliar sob condições de restrição hídrica. Além disso, a queda de folhas senescentes, por si só, também contribui para a redução na biomassa total da planta.

No entanto, observa-se redução expressiva na biomassa total de Alessa, que
B.

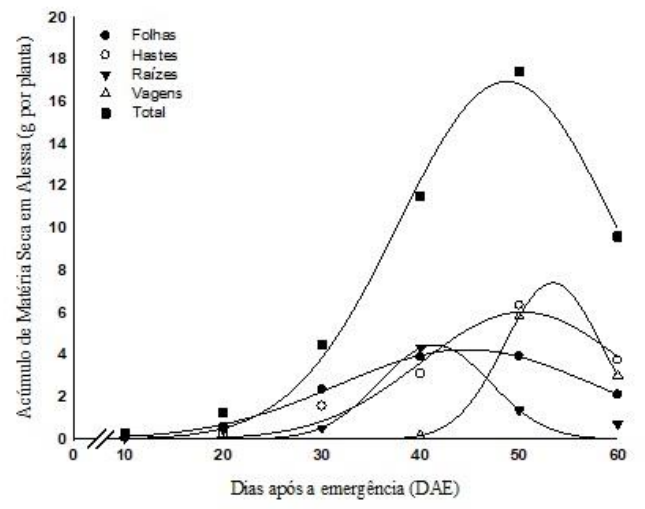

mesmo apresentando um valor máximo superior a UEL-1 (Tabela 2), terminou o ciclo com praticamente a mesma matéria seca acumulada que o segundo genótipo (Figuras $1 \mathrm{~A}$ e 1B). Ao analisar os órgãos separadamente, pode-se notar que este comportamento se deu, principalmente, devido um maior decréscimo na biomassa de vagens em Alessa, enquanto UEL-1 apresentou uma tendência de manutenção da massa de legumes produzida (Figuras 1A e 1B). Gomes et al. (2000) também observaram perda de biomassa de vagens por abscisão nos genótipos de feijão-comum "Xodó" e "A320", semelhante ao relatado por Gomes et al. (2016) avaliando o comportamento de genótipos de feijão-vagem em dois ambientes. 
Tabela 2. Estimativa dos parâmetros de acúmulo de Matéria Seca (MS) nas plantas das cultivares de feijãovagem de crescimento determinado UEL-1 e Alessa em cultivo protegido com fertirrigação.

\begin{tabular}{|c|c|c|c|c|c|}
\hline \multirow{3}{*}{ Parte da planta } & \multicolumn{3}{|c|}{ Estimativas dos parâmetros do modelo ajustado ${ }^{11}$} & \multicolumn{2}{|l|}{$\mathrm{PI}^{(2)}$} \\
\hline & $a$ & $b$ & $x 0$ & $(x 0-b)$ & \multirow{2}{*}{$\mathrm{R}^{2}$} \\
\hline & g planta $^{-1}$ & \multicolumn{3}{|c|}{------- Dias após a emergência (DAE) ------ } & \\
\hline \multicolumn{6}{|c|}{ UEL-1 } \\
\hline Folhas & 3,660 & 13 & 47 & 34 & 0,98 \\
\hline Hastes & 3,731 & 12 & 51 & 39 & 0,99 \\
\hline Raízes & 3,826 & 8 & 42 & 34 & 0,93 \\
\hline Vagens & 4,664 & 7 & 56 & 49 & 0,99 \\
\hline Total & 12,580 & 13 & 50 & 37 & 0,98 \\
\hline \multicolumn{6}{|c|}{ Alessa } \\
\hline Folhas & 4,242 & 13 & 45 & 32 & 0,99 \\
\hline Hastes & 6,020 & 10 & 50 & 40 & 0,96 \\
\hline Raízes & 4,464 & 6 & 41 & 35 & 0,94 \\
\hline Vagens & 7,404 & 5 & 53 & 48 & 0,99 \\
\hline Total & 16,937 & 11 & 49 & 38 & 0,99 \\
\hline
\end{tabular}

${ }^{(1)} a=$ máximo acúmulo $\left(\mathrm{g}\right.$ planta $\left.{ }^{-1}\right) ; x 0=$ valor de $x$, em dias após a emergência (DAE), que proporciona o máximo acúmulo; $b=$ amplitude do intervalo de $x$ entre o ponto de inflexão e o valor de $x 0 .{ }^{(2)} \mathrm{PI}=$ ponto de inflexão.

Como esperado, houve redução na biomassa de raízes após os 40 DAE para ambos genótipos (Figuras 1A e 1B). Na fase reprodutiva, a planta inicia o processo de redistribuição de órgãos fonte (folhas e hastes) para órgãos dreno (vagens) na parte aérea. Assim, as partes reprodutivas não ficam exclusivamente dependentes da absorção por parte das raízes para receberem nutrientes e uma competição por compostos de carbono (componentes majoritários da matéria seca) começa a ocorrer entre esses órgãos, especialmente em plantas leguminosas (ENGELS et al., 2011). Isso está de acordo com as afirmações de Eissenstat e Yanai (1997), de que na maioria das plantas anuais, a maior parte do crescimento de raízes ocorre anteriormente ao florescimento e a morte delas, durante e após o florescimento.

Seguindo o comportamento da matéria seca, o acúmulo de macronutrientes em ambos genótipos foi lento até os 20 DAE. Após esse período, houve aumento progressivo até o ponto de máximo, seguido por redução (Figuras 2 e 3), assim como observado por Barzan et al. (2016) para a maioria dos macronutrientes no genótipo UEL-1 cultivado em condições de campo.

A despeito dos comportamentos similares, a ordem decrescente de máximo acúmulo obtido no presente estudo em condições de cultivo protegido $(\mathrm{N}>\mathrm{K}>\mathrm{Ca}>\mathrm{P}>\mathrm{S}$
$>\mathrm{Mg}$ ), foi distinta daquela reportada por Barzan et al. (2016) em condições de campo $(\mathrm{K}>\mathrm{N}>\mathrm{Ca}=$ $\mathrm{P}>\mathrm{Mg}>\mathrm{S})$. Esta ordem de máximo acúmulo reflete a ordem de concentrações na solução nutritiva (Tabela 1), exceto pelo cálcio, que teve a maior concentração na solução nutritiva, mas apenas o terceiro maior acúmulo dentre os macronutrientes.

O máximo acúmulo para todos os nutrientes avaliados foi obtido entre 48 e 53 DAE (com N e K mais tardiamente aos demais). Assim como o observado para a matéria seca, valores superiores foram obtidos por Alessa em comparação a UEL-1 (Tabela 3). Todavia, a posterior redução na planta como um todo, também em função principalmente do decréscimo no acúmulo das vagens em comparação a UEL-1, aproximou o acúmulo final de ambos cultivares (Figuras 2 e 3 ). Os pontos de inflexão nas curvas de acúmulo da planta como um todo ocorreram dos 34 para os 40 DAE (Tabela 3), reforçando a ideia de que, após entrar na fase reprodutiva, a planta começa a desacelerar as taxas de absorção de nutrientes, mudando para um padrão de remobilização.

As folhas foram a parte que primeiro iniciaram, aos $46 \mathrm{DAE}$, a redistribuição de $\mathrm{N}$ para as vagens em UEL-1, seguido pelas hastes, aos 53 $\mathrm{DAE}$, enquanto as raízes não tiveram papel importante nesse processo (Figura 2A; Tabela 3 ). 
O nitrogênio pode ser transportado a longa distância através dos tecidos na forma de compostos orgânicos, especialmente aminoácidos e peptídeos (LALONDE et al., 2004), como produtos de proteólise para reciclar 0 elemento (GIRONDÉ et al., 2015). A cultivar Alessa apresentou uma remobilização menos pronunciada de $\mathrm{N}$ dos órgãos fonte (Figura 2B), $\mathrm{O}$ que significa que as vagens tiveram de ser mais supridas diretamente pela absorção das raízes e fluxo xilemático. Girondé et al. (2015) também observaram diferenças genotípicas na remobilização de $\mathrm{N}$ em plantas de colza, em que o genótipo "Oase" alocou de forma mais eficiente o $\mathrm{N}$ absorvido em direção às sementes, enquanto o cultivar "Aviso" favoreceu mais a remobilização do nutriente a partir de hastes e folhas.

Este comportamento tem implicações no manejo da fertirrigação, dado que o fertilizante nitrogenado pode ser reduzido para UEL-1 após o início do processo de redistribuição com baixo risco de restrição à nutrição das vagens, enquanto para Alessa, o $\mathrm{N}$ deve ser aplicado continuamente até o ponto de máximo acúmulo pelas vagens, aos 53 DAE (Tabela 3).

Tabela 3. Estimativa dos parâmetros de acúmulo de macronutrientes nas plantas das cultivares de feijãovagem de crescimento determinado UEL-1 e Alessa em cultivo protegido com fertirrigação.

\begin{tabular}{|c|c|c|c|c|c|c|c|c|c|c|}
\hline \multirow{4}{*}{ Parte da planta } & \multicolumn{6}{|c|}{ Estimativas dos parâmetros do modelo ajustado ${ }^{(1)}$} & \multicolumn{2}{|c|}{$\mathrm{PI}^{(2)}$} & \multirow{3}{*}{\multicolumn{2}{|c|}{$\mathrm{R}^{2}$}} \\
\hline & & a & $b$ & & & & & $-b)$ & & \\
\hline & \multicolumn{2}{|c|}{ mg planta $^{-1}$} & \multicolumn{6}{|c|}{---------- Dias após a emergência (DAE) ---------- } & & \\
\hline & UEL-1 & Alessa & UEL-1 & Alessa & UEL-1 & Alessa & UEL-1 & Alessa & UEL-1 & Alessa \\
\hline & \multicolumn{10}{|c|}{ Nitrogênio (N) } \\
\hline Folhas & 200,5 & 182,8 & 12 & 14 & 46 & 44 & 34 & 30 & 0,97 & 0,97 \\
\hline Hastes & 131,7 & 203,7 & 7 & 10 & 53 & 50 & 46 & 40 & 0,93 & 0,94 \\
\hline Raízes & 51,4 & 83,5 & 10 & 9 & 41 & 45 & 31 & 36 & 0,93 & 0,97 \\
\hline Vagens & 212,1 & 413,6 & 7 & 5 & 57 & 53 & 50 & 48 & 0,99 & 0,99 \\
\hline \multirow[t]{2}{*}{ Total } & 457,8 & 714,4 & 14 & 10 & 53 & 50 & 39 & 40 & 0,99 & 0,93 \\
\hline & \multicolumn{10}{|c|}{ Fósforo (P) } \\
\hline Folhas & 17,7 & 18,8 & 11 & 14 & 44 & 44 & 33 & 30 & 0,94 & 0,89 \\
\hline Hastes & 25,8 & 46,9 & 11 & 7 & 49 & 49 & 38 & 42 & 0,99 & 0,94 \\
\hline Raízes & 13,6 & 21,5 & 10 & 5 & 40 & 41 & 30 & 36 & 0,90 & 0,91 \\
\hline Vagens & 28,6 & 60,8 & 6 & 5 & 54 & 53 & 48 & 48 & 0,99 & 0,99 \\
\hline \multirow[t]{2}{*}{ Total } & 69,4 & 113,5 & 12 & 9 & 49 & 49 & 37 & 40 & 0,99 & 0,94 \\
\hline & \multicolumn{10}{|c|}{ Potássio (K) } \\
\hline Folhas & 108,4 & 98,7 & 12 & 14 & 47 & 46 & 35 & 32 & 0,98 & 0,97 \\
\hline Hastes & 168,9 & 291,4 & 12 & 10 & 51 & 50 & 39 & 40 & 0,99 & 0,96 \\
\hline Raízes & 45,3 & 69,4 & 9 & 5 & 36 & 40 & 27 & 35 & 0,87 & 0,93 \\
\hline Vagens & 180,1 & 259,0 & 7 & 5 & 56 & 53 & 49 & 48 & 0,99 & 0,99 \\
\hline \multirow[t]{2}{*}{ Total } & 409,5 & 606,1 & 14 & 9 & 53 & 50 & 39 & 41 & 0,99 & 0,96 \\
\hline & \multicolumn{10}{|c|}{ Cálcio (Ca) } \\
\hline Folhas & 137,6 & 142,8 & 11 & 15 & 49 & 47 & 38 & 32 & 0,94 & 0,84 \\
\hline Hastes & 79,0 & 87,1 & 12 & 15 & 50 & 51 & 38 & 36 & 0,99 & 0,97 \\
\hline Raízes & 16,9 & 16,8 & 12 & 10 & 42 & 40 & 30 & 30 & 0,88 & 0,92 \\
\hline Vagens & 28,8 & 50,4 & 6 & 5 & 53 & 52 & 47 & 47 & 0,99 & 0,99 \\
\hline \multirow[t]{2}{*}{ Total } & 250,3 & 271,5 & 12 & 14 & 49 & 48 & 37 & 34 & 0,98 & 0,89 \\
\hline & \multicolumn{10}{|c|}{ Magnésio (Mg) } \\
\hline Folhas & 8,4 & 12,6 & 14 & 13 & 46 & 48 & 32 & 35 & 0,92 & 0,97 \\
\hline Hastes & 7,1 & 6,9 & 11 & 14 & 49 & 49 & 38 & 35 & 0,99 & 0,91 \\
\hline Raízes & 7,4 & 12,0 & 8 & 5 & 39 & 39 & 31 & 35 & 0,94 & 0,96 \\
\hline Vagens & 9,3 & 16,3 & 7 & 5 & 56 & 53 & 49 & 48 & 0,99 & 0,99 \\
\hline Total & 24,4 & 35,0 & 14 & 12 & 49 & 48 & 35 & 36 & 0,97 & 0,99 \\
\hline
\end{tabular}




\begin{tabular}{ccccccccccc}
\hline & \multicolumn{10}{c}{ Enxofre (S) } \\
\hline Folhas & 10,2 & 10,5 & 11 & 15 & 45 & 45 & 34 & 30 & 0,97 & 0,96 \\
Hastes & 11,0 & 15,2 & 14 & 13 & 54 & 51 & 40 & 38 & 0,99 & 0,92 \\
Raízes & 11,1 & 18,6 & 9 & 5 & 40 & 40 & 31 & 35 & 0,84 & 0,93 \\
Vagens & 8,1 & 16,1 & 7 & 5 & 54 & 53 & 47 & 48 & 0,99 & 0,99 \\
Total & 32,9 & 43,7 & 13 & 13 & 48 & 48 & 35 & 35 & 0,98 & 0,99 \\
\hline
\end{tabular}

(1) $\bar{a}=$ máximo acúmulo $\left(\mathrm{mg}\right.$ planta $\left.^{-1}\right) ; x 0=$ valor de $x$, em dias após a emergência (DAE), que proporciona o máximo acúmulo; $b=$ amplitude do intervalo de xentre o ponto de inflexão e o valor dexo. ${ }^{(2)} \mathrm{PI}=$ ponto de inflexão.

Figura 2. Acúmulo (mg planta ${ }^{-1}$ ) de nitrogênio $(N)$, fósforo $(P)$ e potássio $(K)$ do feijão-vagem, genótipos UEL-1 e Alessa, nas diferentes partes da planta ao longo do ciclo, em cultivo protegido com fertirrigação.

A.

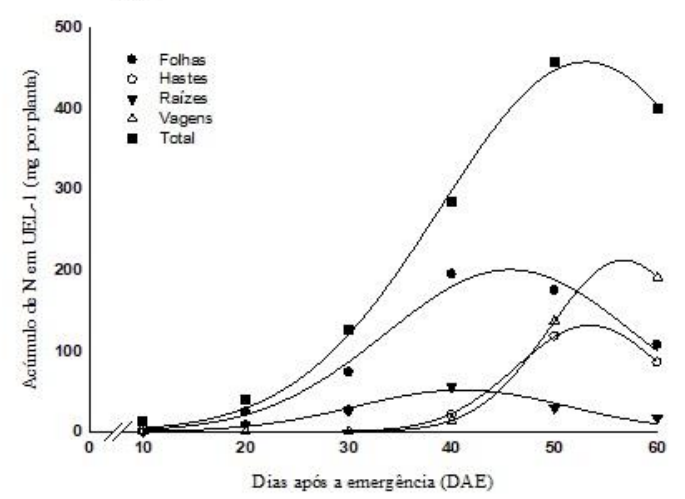

C.

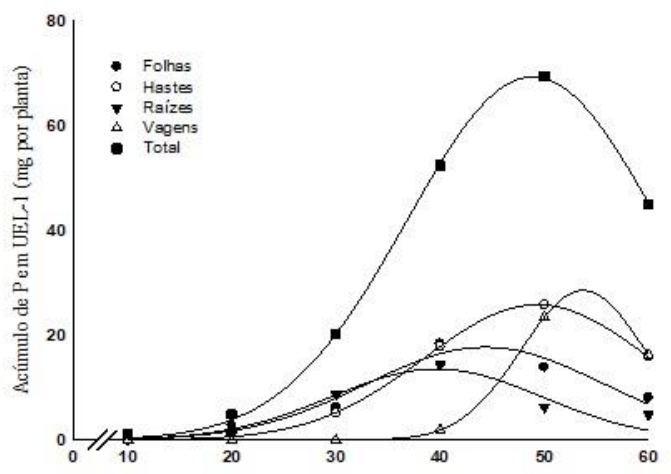

E.

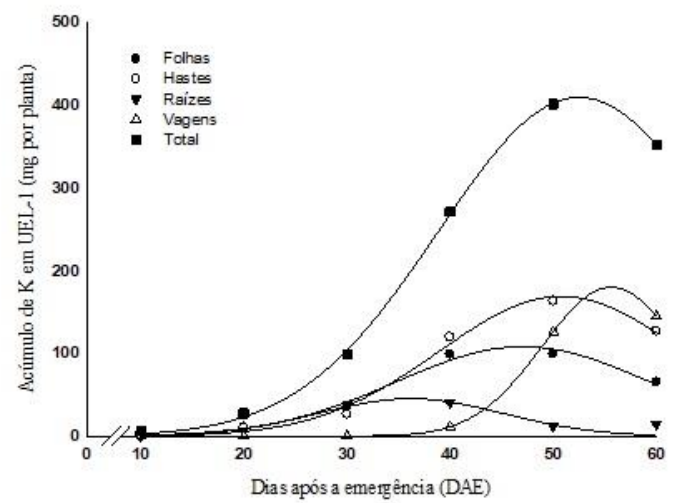

B.

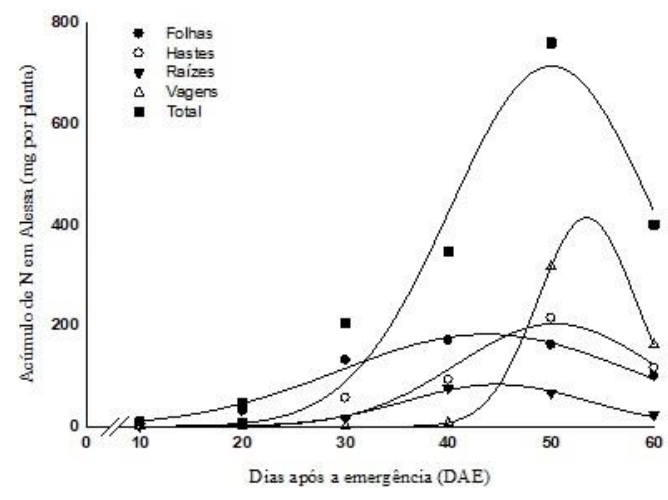

D.

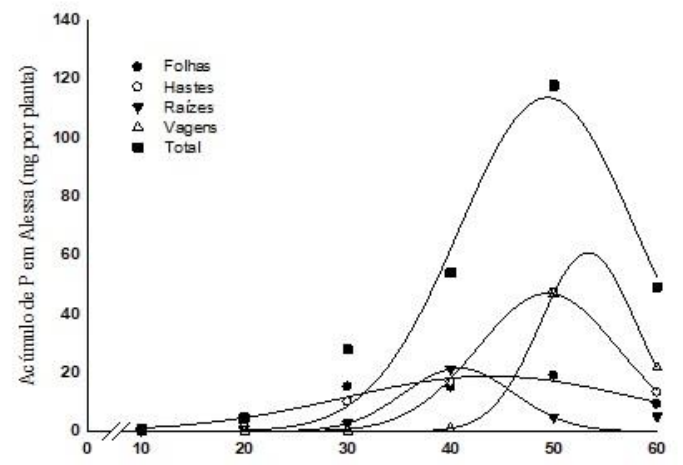

F.

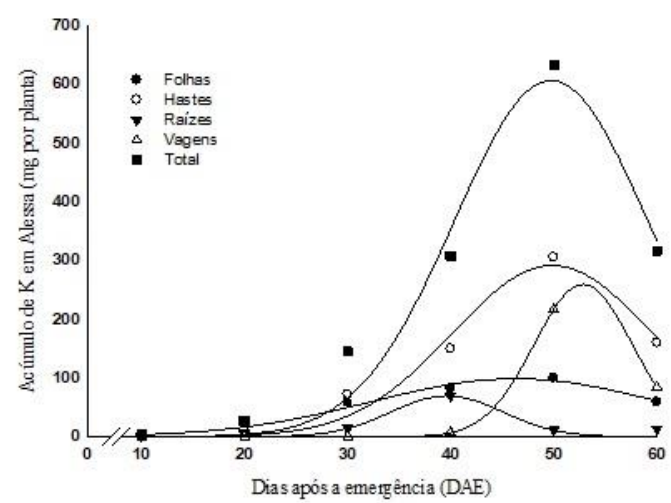


As folhas, hastes e raízes atuaram de forma semelhante na redistribuição de fósforo para as vagens em UEL-1 (Figura $2 \mathrm{C}$ ). Já a cultivar Alessa demonstrou dinâmica diferente de compartimentalização do $\mathrm{P}$, em que as hastes e raízes, especialmente as primeiras, foram as principais partes a enviar fósforo para as vagens, enquanto as folhas pouco transferiram o $P$ acumulado (Figura 2D). Como ocorreu para N, o decréscimo no acúmulo de $P$ das vagens foi mais pronunciado para Alessa, devido à perda de biomassa por abscisão desse órgão. Comportamento particular observado neste estudo foi que o acúmulo de $P$ para os dois genótipos não ocorreu de forma contínua até o final do ciclo (Figuras 2C e 2D), diferentemente do que foi reportado tanto para feijão-vagem em condições de campo (BARZAN et al., 2016) como para feijão-comum (PEGORARO et al., 2014). Ao contrário, o acúmulo na planta toda alcançou valor máximo aos 49 DAE (Tabela 3) com posterior decréscimo.

Entre os órgãos vegetativos, as hastes tiveram o maior acúmulo de potássio em ambos genótipos (Tabela 3), mais notavelmente para Alessa (Figura 2F). Além disso, a mobilização para as vagens ocorreu principalmente a partir das hastes; apesar de as folhas também terem apresentado contribuição considerável, em especial para UEL-1 (Figura 2E). O K ${ }^{+}$é o principal cátion no floema (LEMOINE et al., 2013), uma vez que apresenta um importante papel no transporte de solutos nos tecidos vasculares (MAATHUIS, 2009). Este nutriente atua diretamente no transporte a longa distância de açúcares (AHMAD; MAATHUIS, 2014) e nitrato (WHITE, 2011). Com isso, não coincidentemente é que o $\mathrm{K}$ foi encontrado nas hastes em elevadas quantidades.
O cálcio foi o nutriente mais peculiar, sendo acumulado em maior proporção nos órgãos vegetativos (especialmente folhas) da parte aérea em comparação às vagens, para ambos genótipos (Figuras 3A e 3B). O máximo acúmulo de $\mathrm{Ca}$ nas vagens não atingiu $20 \%$ do acumulado na planta toda (Tabela 3). Isso ocorre pois o suprimento de cálcio à parte aérea está mais intimamente relacionado ao fluxo xilemático movido pela transpiração (WHITE, 2001; GILLIHAM et al., 2011). Como as folhas apresentam 10 a 100 vezes mais frequência estomática que os frutos (ASCHAN; PFANZ, 2003), a taxa de transpiração é bastante superior, o que leva a um maior acúmulo de Ca comparado aos frutos (tecidos alimentados mais pelo floema), nos quais o nutriente tende a se apresentar em baixas concentrações (KARLEY; WHITE, 2009). Assim, a baixa mobilidade de Ca no floema impõe uma restrição ao acúmulo deste nutriente em órgãos com baixa transpiração, como as vagens (CONN; GILLIHAM, 2010).

Magnésio e enxofre tiveram acúmulo relativamente elevado nas raízes para ambos genótipos, comparados aos outros macronutrientes, de forma que este órgão desempenhou papel importante para o estoque temporário destes nutrientes, com posterior redistribuição para as vagens (Figuras 3C, 3D, 3E e 3F). Esta pode ser uma evidência de excesso de disponibilidade desses nutrientes, visto que de acordo com Maathuis (2009), os elementos nessa condição são tipicamente estocados no vacúolo central, sendo liberados conforme a necessidade citoplasmática. 
Figura 3. Acúmulo (mg planta ${ }^{-1}$ ) de cálcio (Ca), magnésio (Mg) e enxofre (S) do feijão-vagem, genótipos UEL1 e Alessa, nas diferentes partes da planta ao longo do ciclo, em cultivo protegido com fertirrigação.

A.

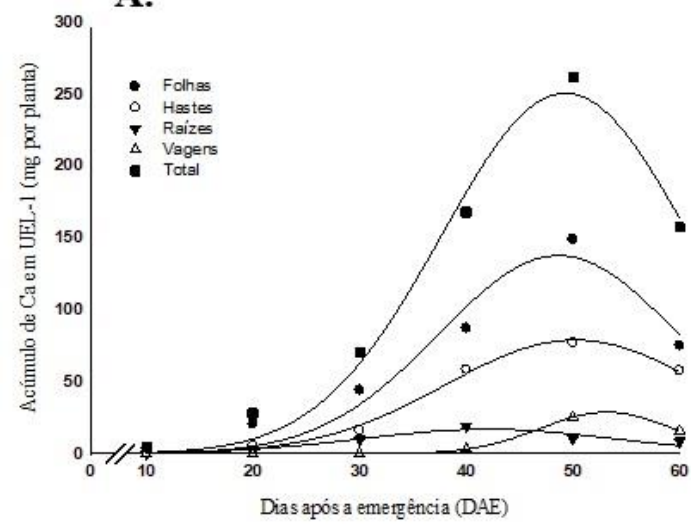

C.

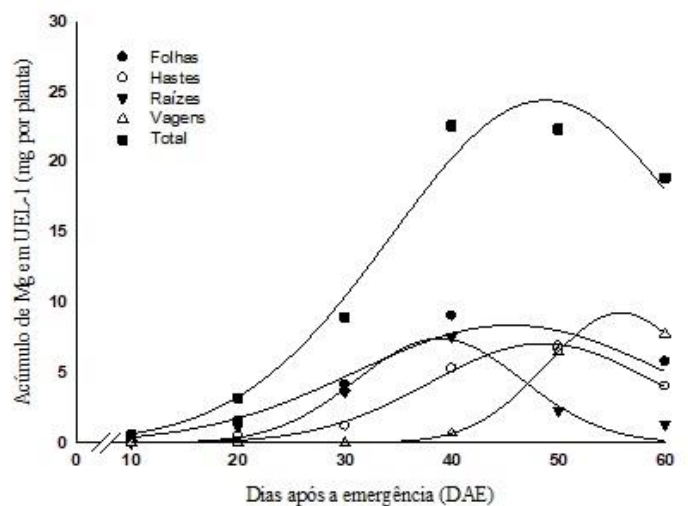

E.

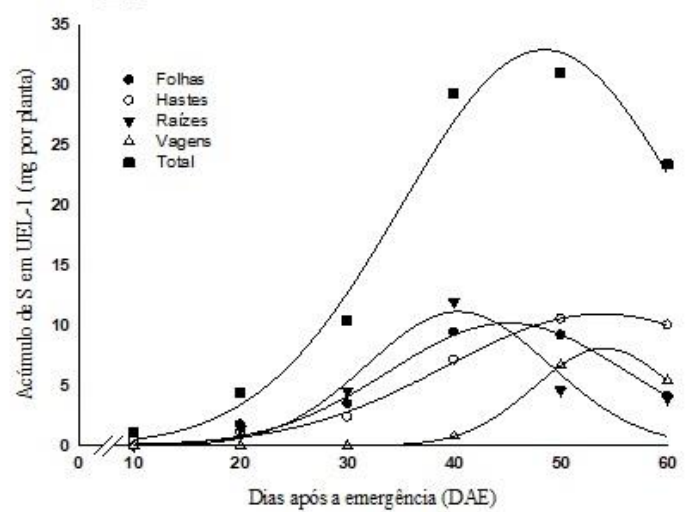

Diferentemente do que aconteceu para o potássio, ambos cultivares acumularam mais $\mathrm{Mg}^{2+}$ nas folhas comparado as hastes (Tabela 3), pois ao contrário do $\mathrm{K}^{+}$, que é relativamente abundante em tecidos de transporte, a maioria do magnésio metabolicamente ativo está localizado nos cloroplastos (HERMANS et al., 2013), mais presentes em órgãos com função fotossintética. Além disso, $\mathrm{Mg}^{2+}$ é também um elemento móvel no floema e, logo, prontamente translocado para frutos, sementes e tubérculos (KARLEY; WHITE, 2009). O enxofre foi outro
B.

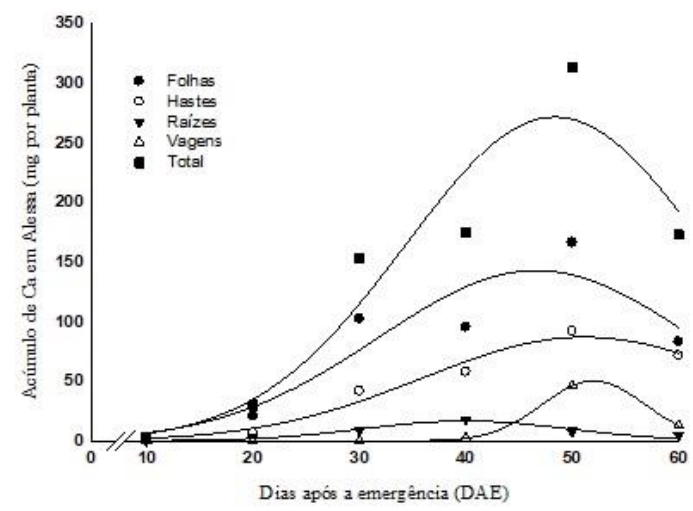

D.

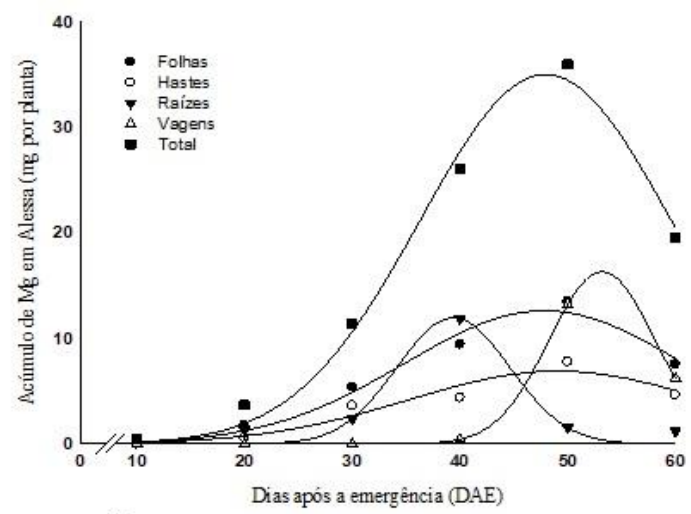

F.

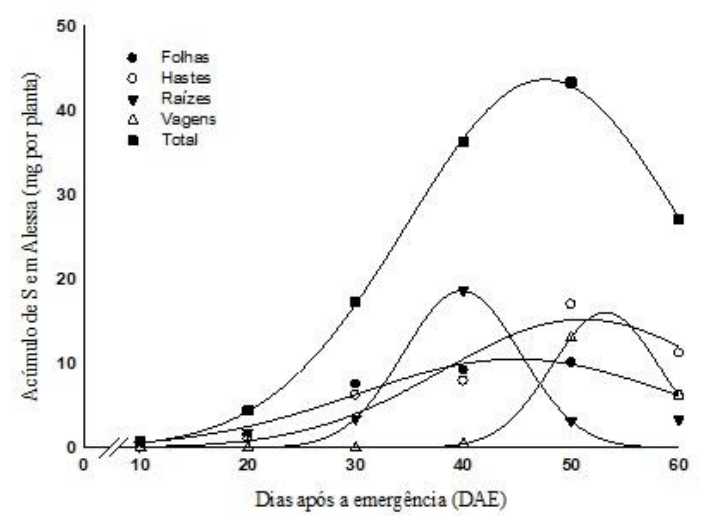

nutriente em que o máximo acúmulo foi maior nas hastes comparado as folhas para ambos genótipos (Tabela 3). Este é absorvido pelas plantas como $\mathrm{SO}_{4}{ }^{2-}$, sendo rapidamente transportado via xilema para a parte aérea, onde é reduzido nos cloroplastos, incorporado ao aminoácido cisteína e parcialmente móvel no floema na forma do peptídeo glutationa (Glu-CysGly) (MAATHUIS, 2009).

O desempenho produtivo de vagens frescas foi estimado em 2,07 e 1,52 $\mathrm{kg} \mathrm{m}^{-2}$, respectivamente para UEL-1 e Alessa. Esses 
valores podem ser considerados elevados para genótipos de crescimento determinado, mesmo se considerando o sistema de cultivo adotado (fertirrigação em ambiente protegido), uma vez que Basso et al. (2012) obtiveram máxima produtividade de $1,09 \mathrm{~kg} \mathrm{~m}^{-2}$ no mesmo sistema, utilizando o genótipo UEL-2, também de crescimento determinado. Ao considerar que o genótipo Alessa apresentou maior absorção de todos os macronutrientes, bem como acúmulo de biomassa superior à UEL-1 e, ainda assim, tenha obtido produtividade de vagens frescas inferior a este último, pode-se atribuir menor eficiência à Alessa, tanto no uso de fotoassimilados quanto dos elementos minerais estudados.

\section{Conclusões}

Em cultivo protegido fertirrigado, para ambos genótipos de feijão-vagem de crescimento determinado, UEL-1 e Alessa, o $\mathrm{N}$ apresenta o maior acúmulo, seguido por $\mathrm{K}, \mathrm{Ca}, \mathrm{P}, \mathrm{S}$ e $\mathrm{Mg}$, com a partição entre os órgãos da planta ao longo do tempo sendo semelhante nos dois cultivares. Por outro lado, existem diferenças genotípicas nas quantidades acumuladas de biomassa e macronutrientes, ambos superiores na cultivar Alessa, enquanto UEL-1 demonstra ter melhor eficiência no uso desses elementos, considerando-se a maior produtividade de vagens frescas obtida por este cultivar mesmo tendo apresentado menor acúmulo de matéria seca e nutrientes.

\section{Referências}

AHMAD, I.; MAATHUIS, F. J. M. Cellular and tissue distribution of potassium: physiological relevance, mechanisms and regulation. Journal of Plant Physiology, v. 171, n. 9, p. 708-714, 2014. https://doi.org/10.1016/i.jplph.2013.10.016.

ARAÚJO, A. P.; TEIXEIRA, M. G. Variabilidade dos índices de colheita de nutrientes em genótipos de feijoeiro e sua relação com a produção de grãos. Revista Brasileira de Ciência do Solo, v.36, p. 137-146, 2012.

http://www.scielo.br/pdf/rbcs/v36n1/v36n1a15. pdf

ASCHAN, G.; PFANZ, H. Non-foliar photosynthesis - a strategy of additional carbon acquisition. Flora, v. 198, n. 2, p. 81-97, 2003. https://doi.org/10.1078/0367-2530-00080
BARZAN, R. R.; MONTANUCCI, W. G.; FREGONEZI, G. A. F.; FURLAN, F. F.; ALMEIDA, L. H. C.; MARTINI, G. F. A.; TAKAHASHI, L. S. A.; TAKAHASHI, $\mathrm{H}$. W. Macronutrients requirement of a snap bean genotype with determinate growth habit in Brazil. African Journal of Agricultural Research, v. 11, n. 8, p. 644-651, 2016. https://doi.org/10.5897/AJAR2015.10486.

CONN, S.; GILLIHAM, M. Comparative physiology of elemental distributions in plants. Annals of Botany, v. 105, n. 7, p. 1081-1102, 2010. http://doi.org/10.1093/aob/mcq027.

EISSENSTAT, D. M.; YANAI, R. D. The ecology of root lifespan. Advances in Ecological Research, v. 27 , p. 1-60, 1997. https://doi.org/10.1016/S00652504(08)60005-7.

ENGELS, C.; KIRKBY, E.; WHITE, P. Mineral nutrition, yield and source-sink relationships. In: MARSCHNER, P. (Org.). Marschner's mineral nutrition of higher plants. 3. ed. Waltham: Academic Press, 2011. p. 85-133.

FERNANDES, C.; ARAÚJO, J. A. C.; CORÁ, J. E. Impacto de quatro substratos e parcelamento da fertirrigação na produção de tomate sob cultivo protegido. Horticultura Brasileira, v. 20, n. 4., p. 559-563, 2002. http://dx.doi.org/10.1590/S010205362002000400010.

GILLIHAM, M.; DAYOD, M.; HOCKING, B. J.; XU, B.; CONN, S. J.; KAISER, B. N.; LEIGH, R. A.; TYERMAN, S. D. Calcium delivery and storage in plant leaves: exploring the link with water flow. Journal of Experimental Botany, v. 62, n. 7, p. 2233-2250, 2011. http://doi.org/10.1093/jxb/err111.

GIRONDÉ, A.; ETIENNE, P.; TROUVERIE, J.; BOUCHEREAU, A.; CAHÉREC, F. L.; LEPORT, L.; ORSEL, M.; NIOGRET, M. F.; NESI, N.; CAROLE, D.; SOULAY, F.; MASCLAUX-DAUBRESSE, C.; AVICE, J. C. The contrasting $\mathrm{N}$ management of two oilseed rape genotypes reveals the mechanisms of proteolysis associated with leaf $\mathrm{N}$ remobilization and the respective contributions of leaves and stems to $\mathrm{N}$ storage and remobilization during seed filling. BMC Plant Biology, v. 15, n. 59, p. 121, 2015. https://doi.org/10.1186/s12870-0150437-1.

GOMES, A. A.; ARAÚJO, A. P.; ROSSIELLO, R. O. P.; PIMENTEL, C. Acumulação de biomassa, 
características fisiológicas e rendimento de grãos em cultivares de feijoeiro irrigado e sob sequeiro. Pesquisa Agropecuária Brasileira, v. 35, n. 10, p. 1927-1937, 2000.

http://www.scielo.br/pdf/pab/v35n10/35n10a03 .pdf

GOMES, G. R.; MORITZ, A.; FREIRIA, G. H.; FURLAN, F. F.; TAKAHASHI, L. S. A. Desempenho produtivo de genótipos de feijão-vagem arbustivo em dois ambientes. Scientia Agropecuaria, v. 7, n. 2, p. 85-92, 2016.

http://dx.doi.org/http://10.17268/sci.agropecu.2 $\underline{016.02 .01 .}$.

HELDWEIN, A. B.; STRECK, N. A.; STURZA, V. S.; LOOSE, L. H.; ZANON, A. J.; TOEBE, M.; SOUZA, A. T.; PETERS, M. B.; KARLEC, F. Plastocrono e rendimento de feijão-vagem cultivado sob ambiente protegido e no ambiente externo em semeadura tardia no outono. Ciência Rural, v. 40, n. 4, p. 768-773, 2010.

http://dx.doi.org/10.1590/S0103-

$\underline{84782010005000045 .}$.

HERMANS, C.; CONN, S. J.; CHEN, J.; XIAO, Q.; VERBRUGGEN, N. An update on magnesium homeostasis mechanisms in plants. Metallomics, v. 5, n. 9, p. 1170-1183, 2013.

http://doi.org/10.1039/c3mt20223b.

KARLEY, A. J.; WHITE, P. J. Moving cationic minerals to edible tissues: potassium, magnesium, calcium. Current Opinion in Plant Biology, v. 12, n. 3, p. 291-298, 2009.

http://doi.org/10.1016/j.pbi.2009.04.013.

LALONDE, S.; WIPF, D.; FROMMER, W. B. Transport mechanisms for organic forms of carbon and nitrogen between source and sink. Annual Review of Plant Biology, v. 55, p. 341372, 2004.

http://doi.org/10.1146/annurev.arplant.55.03190 3.141758.

LEMOINE R.; CAMERA, S. L.; ATANASSOVA, R.; DÉDALDÉCHAMP, F.; ALLARIO, T.; POURTAU, N.; BONNEMAIN, J. L.; LALOI, M.; COUTOSTHÉVENOT, P.; MAUROUSSET, L.; FAUCHER, M.; GIROUSSE, C.; LEMONNIER, P.; PARRILLA, J.; DURAND, M. Source-to-sink transport of sugar and regulation by environmental factors. Frontiers in Plant Science, v. 4, n. 272, p. 272-
293, 2013.

http://doi.org/10.3389/fpls.2013.00272.

MAATHUIS, F. J. M. Physiological functions of mineral macronutrients. Current Opinion in PlantBiology, v. 12, n. 3, p. 250-258, 2009. https://doi.org/10.1016/j.pbi.2009.04.003.

MALAVOLTA, E.; VITTI, G. C.; OLIVEIRA, S. A. Avaliação do estado nutricional das plantas: princípios e perspectivas. Piracicaba: POTAFOS, 1997. $319 \mathrm{p}$.

MOREIRA, R. M. P.; FERREIRA, J. M.; TAKAHASHI, L. S. A.; VASCONCELOS, M. E. C.; GEUS, L. C.; BOTTI, L. Potencial agronômico e divergência genética entre genótipos de feijão-vagem de crescimento determinado. Semina: Ciências Agrárias, v. 30, supl. 1, p. 1051-1060, 2009.

http://www.uel.br/revistas/uel/index.php/semag rarias/article/download/4641/3947.

PEGORARO, R. F.; OLIVEIRA, D.; MOREIRA, C. G.; KONDO, M. K.; PORTUGAL, A. F. Partição de biomassa e absorção de nutrientes pelo feijoeiro comum. Caatinga, v. 27, n. 3, p. 41-52, 2014. http://www.redalyc.org/articulo.oa?id=23713210 $\underline{4005}$.

SILVA, A. O. A fertirrigação e o processo de salinização de solos em ambiente protegido. Nativa, v. 2, n. 3, p. 180-186, 2014.

http://doi.org/10.14583/2318-7670.v02n03a10.

WHITE, P. J. Long-distance transport in the xylem and phloem. In: MARSCHNER, P. (Org.).

Marschner's mineral nutrition of higher plants. Waltham: Academic Press, 2011. p. 49-70.

WHITE, P. J. The pathways of calcium movement to the xylem. Journal of Experimental Botany, v.52, n. 358, p. 891-899, 2001.

http://doi.org/10.1093/jexbot/52.358.891.

ZOBIOLE, L. H. S.; CASTRO, C.; OLIVEIRA, F. A.; OLIVEIRA JÚNIOR, A. Marcha de absorção de macronutrientes na cultura do girassol. Revista Brasileira de Ciência do Solo, v. 34, n. 2, p. 425433, 2010. http://dx.doi.org/10.1590/s0100$\underline{06832010000200016 .}$. 